\title{
Seasonal Reproductive Biology of Gilthead Seabream (Sparus aurata)
}

\author{
Salah M. Aly ${ }^{1}$, Safaa M. Sharaf ${ }^{2}$ and Alaa Sh. Griesh ${ }^{3}$ \\ ${ }^{1}$ Department of Pathology, Faculty of Vet. Medicine, Suez Canal University, \\ Ismailia, Egypt. ${ }^{2}$ Department of Animal Production and Fish Resources, \\ Faculty of Agriculture, Suez Canal University, Ismailia, Egypt. ${ }^{3}$ Aquatic \\ Hatchery Production Department, Fish Farming and Technology Institute, \\ Suez Canal University, Ismailia, Egypt.
}

\begin{abstract}
:
The purpose of the study is to investigate the effect of sex and season on reproduction of Gilthead seabream (Sparus aurata). A total of 88 sexually mature $S$. aurata fish were collected from natural habitat, Manzalah lake Damietta, Egypt during the period from March, 2017 to September, 2018. Fish were maintained in aquaria for $24 \mathrm{~h}$ at appropriate environment according to each season. The results of the study showed high condition factor in male, females and hermaphrodites in winter. Gonadosomatic index (GSI) recorded high value in hermaphrodite in winter and hepatosomatic index (HSI) was high in females in winter. The absolute fecundity was higher in autumn than winter while the egg diameter was higher in winter than autumn. It could be concluded that, spawning was prevalent during winter season and triggered by lower water temperatures.
\end{abstract}

Key words: Sparus aurata, Reproduction, Seasonal variations.

\section{Introduction:}

Gillthead seabream $S$. aurata is locally known as "denis" and exploited by the trawl fishery. It contributed about $3 \%$ of the total trawl landings in the Port Said fishery (Mehanna, 2007). Gilthead seabream, S. aurata (Linnaeus, 1758) is common throughout the Mediterranean and considered as one of the most popular porgies for food. It is a bottom dwelling species and usually lives solitary or in small and loose groups. It is an expensive luxury food so; it is a target for intensive fishing. Recently, it has been widely cultured in many countries including Egypt. In the wild it spawns in the winter months but in aquaculture farms it is conditioned to breed all year round under controlled methods (Morretti, 1999 and Loris, 2005 ).

The gilthead sea bream is a protandrous hermaphrodite: it is in the first two years, it is a functional male and turns to females when length over $30 \mathrm{~cm}$. During the male phase, the bisexual gonad has functional testicular areas with asynchronous spermatogenesis and nonfunctional ovarian areas (Zohar, 1989). In the Mediterranean, the reproduction begins from October to December. Ovarian development is also asynchronous, and females are batch spawners that can lay 20000-80000 
eggs per day for up to 3 months. The eggs are spherical and pelagic, with a diameter slightly lower than $1 \mathrm{~mm}$ and a single large oil droplet. The planktonic larval stage lasts about 50 days at 17$18^{\circ} \mathrm{C}$ (Sola et al., 2006).

The aim of the present study is to investigate the effect of sex and season on reproduction of Gilthead seabream, S. aurata through determination of gonadosomatic index, hepatosomatic index, Fecundity and egg diameter.

\section{Materials and Methods}

The present work was conducted at Fish Farming and Technology Institute, Suez Canal University. A total of 88 sexually mature gilthead seabream ( $S$. aurata) fish were collected from natural habitat, Manzalah lake Damietta, Egypt during the period from March, 2017 to September, 2018. About 2r Fish collected in each season and were maintained in aquaria for $24 \mathrm{~h}$ at appropriate environment according to each season. After that, all fish were netted, anesthetized using clove oil 40 mg / L (Mylonas et al., 2005). Body weight, total length and sex of each fish were determined.

Samples of fish were weighed (wet weight) and recorded to the nearest gram. The length of each fish obtained. Total length was taken according to Anderson et al. (1983). The Fulton's condition factor $(\mathrm{k})$, which relates body length of the fish to the body weight, was calculated according to (Hastings and Dickie, 1972) as follows:

Condition factor $(\mathrm{K})=\mathbf{1 0 0} \times \mathrm{W} / \mathrm{L3}$

Where; $\mathrm{W}=$ body weight in $(\mathrm{g})$

$\mathrm{L}=$ body length in $(\mathrm{cm})$
The Gonado-somatic index (GSI) is a method for studying the spawning season by following the seasonal changes in the gonad weight in relation to the body weight (Bal and Rao, 1984). GSI was determined by the following formula

\section{GSI = GW / BW x 100 (Albertine- Berhaut, 1973) \\ $\mathrm{GW}=$ wet weight of the gonad $\mathrm{BW}=$ body weight of the fish}

Absolute fecundity is the number of ripe eggs produced by a female in one spawning season or year (this is the usual meaning when the general term fecundity" is used, although on occasion it might also mean the number of eggs produced in a lifetime) (Hunter, 1992).

Fecundity = (no of eggs $x$ weight of gonad) / weight of gonad sample

Oocyte diameter frequency helps to understand the nature of reproduction. It gives the information on either the fish contributes once or several times in the breading season (Amein, 1996). Oocyte were separated from ovarian tissues and put in a saline solution $(0.9 \% \mathrm{NaCl})$ then, they were taken into slide. Oocyte diameter was measured to the nearest $0.01 \mu \mathrm{m}$ by using an eye- piece $\mu \mathrm{m}$ on the binuclear microscope at a power magnification of 4 X.50 oocytes were taken randomly to determine the seasonaly mean oocyte diameter.

The hepato-somatic index (HSI) is associated with the liver energetic reserves and metabolic activity, The HSI gives us information about the condition of liver and body. HSI was determined by the following formula:

\section{HSI $=\mathbf{L W} / \mathbf{B W} \times 100$}

$\mathrm{LW}=$ wet weight of the liver 
$\mathrm{BW}=$ body weight of the fish

\section{Statistical Analysis}

Statistical analysis was performed using the $3 \times 4$ factorial design according to the following model: $Y_{\mathrm{ijk}}=\mu+G_{i}+S_{j}$ $+\mathrm{Gi}_{\mathrm{i}} \mathrm{S}_{\mathrm{j}}+\mathrm{e}_{\mathrm{ijk}}$

Where: $\boldsymbol{\mu}$ is the overall mean,

$\mathbf{G}_{\mathbf{i}}$ is the fixed effect of the gender ( $\mathrm{I}=$ $1 . .3)$,

$\mathbf{S}_{\mathrm{j}}$ is the fixed effect of the season of the year $(j=1 \ldots . .4)$,

$\mathbf{G}_{\mathbf{i}} \mathbf{S}_{\mathbf{j}}$ is the interaction between effect of the gender and season and

$\mathbf{e}_{\mathrm{ijk}}$ is random error.

Values are given as Mean \pm SE. Mean was tested for significant differences at P-values $\leq 0.05$ (Duncan, 1955) to determine the effects of gender, and season on biological and physiological parameters. Some other values were subjected to one-way ANOVA. All the statistical analyses were calculated using SPSS program version 20 (SPSS, Richmond, USA) as described by Dytham (1999).

\section{Results}

\section{Fish age}

About 7 females were collected in the age I year, no males were collected in the same age. While age II year, 10 females were collected and 4 males. During age III year about 19 females, 6 males and 8 hermaphrodite fish were found. Age IV year, 21 females, 5 males and 6 hermaphrodite were obtained. Two fish were found during age $\mathrm{V}$ year as shown in figure (1).

\section{Weight, Length and $k$ factor:}

In the current study, body weight were documented for different gender and at various seasons even among the same season individually. Concerning the combined effects of gender and season, the highest value of body weight was documented in females at spring $(445.88 \mathrm{~g})$ and autumn (427.36 g) and in hermaphrodites at different seasons. But the lowest values were recognized in males at different seasons, as shown in figures (2).

In the present investigations, the lowest value of length of fish specimens captured $(23.00 \mathrm{~cm})$ in spring in males. Due to the combined effects of gender and season, average total length was higher in females and hermaphrodites than in males, as shown in figures (3).

In the present investigations, the highest value of $\mathrm{k}$ factor of fish specimens captured $(2.06 \%)$ in hermaphrodites at winter. Due to the combined effects of gender and season, average total $\mathrm{k}$ factor higher in females and hermaphrodites than in males, as shown in figures (4).

\section{Gonadosomatic (GSI) and} Hepatosomatic (HSI) Index:

In the present study, gonad weight were documented for different gender and at various seasons and even among the same season individually. Concerning the combined effects of gender and season, the highest value of gonad weight and GSI was documented in hermaphrodites at winter (48.23 $\mathrm{g}$ and $14.47 \%$ respectively) as shown in figures (5 and 6).

In the present investigations, the highest value of liver weight of fish specimens captured $(11.07 \%)$ in females at autumn. Due to the interaction of gender and season, average total liver weight was significantly $(\mathrm{P} \leq 0.05)$ higher in 
females and hermaphrodites than in males, as shown in figure (7).

In the present observations, the highest value of HSI of fish specimens was recorded $(2.76 \%)$ in females at winter. The lowest values were recorded in males at spring $(0.76 \%)$ as shown in figures (8).

\section{Fecundity:}

Fecundity is the number of eggs which released by female in the spawning season. Absolute fecundity is the total number of mature eggs in the ovary and relative fecundity is total no. of eggs per unit of fish length or fish weight. Absolute fecundity was higher in autumn $\left(400 \times 10^{3}\right)$ than in winter $(300$ $\mathrm{x} 10^{3}$ ), as shown in figure (9).

\section{Egg diameter}

The egg diameter indicate the time of the spawning of given fish species. No eggs was observed in summer and spring. The value of egg diameter was recorded in autumn and winter 0.45 and $0.46 \mathrm{~mm}$ respectively as shown figure (10).

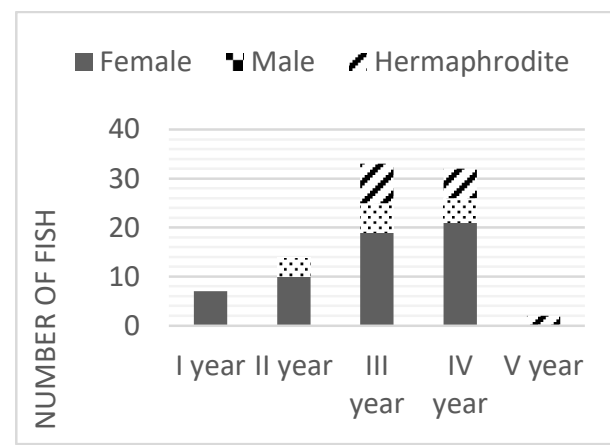

Figure (1): Sex of gilthead seabream S. aurata according to age for the collected samples

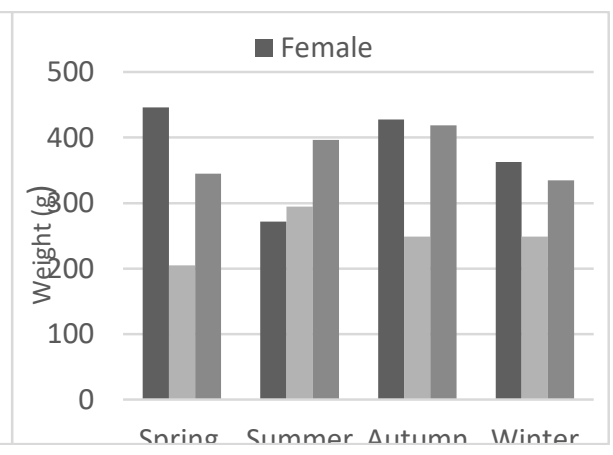

Figure (2): Body weight values (g) of different gender of Gilthead sea bream $S$. aurata specimens collected in different seasons.

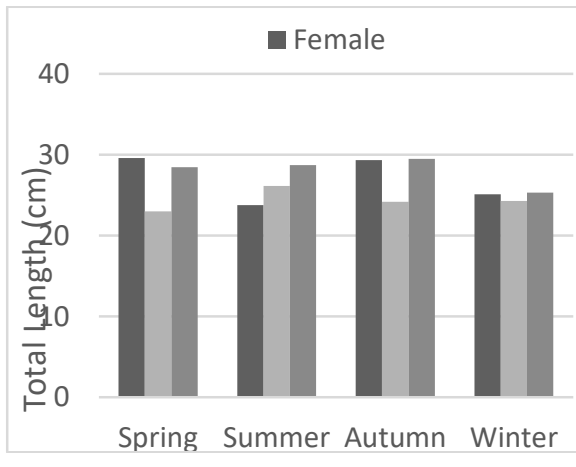

Figure (3): Total length values (cm) of different gender of Gilthead sea bream $S$. aurata specimens collected in different seasons.

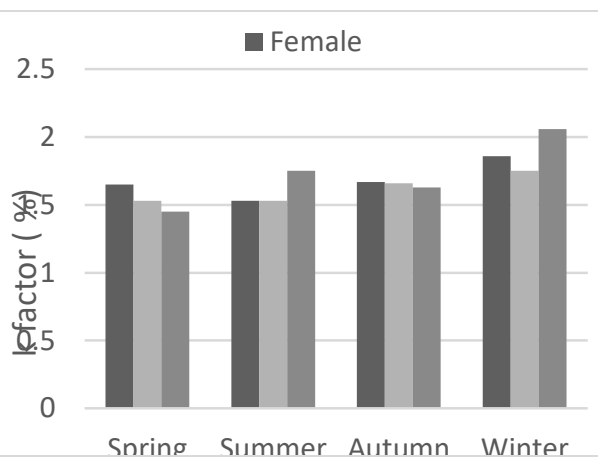

Figure (4): $\mathrm{K}$ factor values (\%) of different gender of Gilthead sea bream $S$. aurata specimens collected in different seasons. 

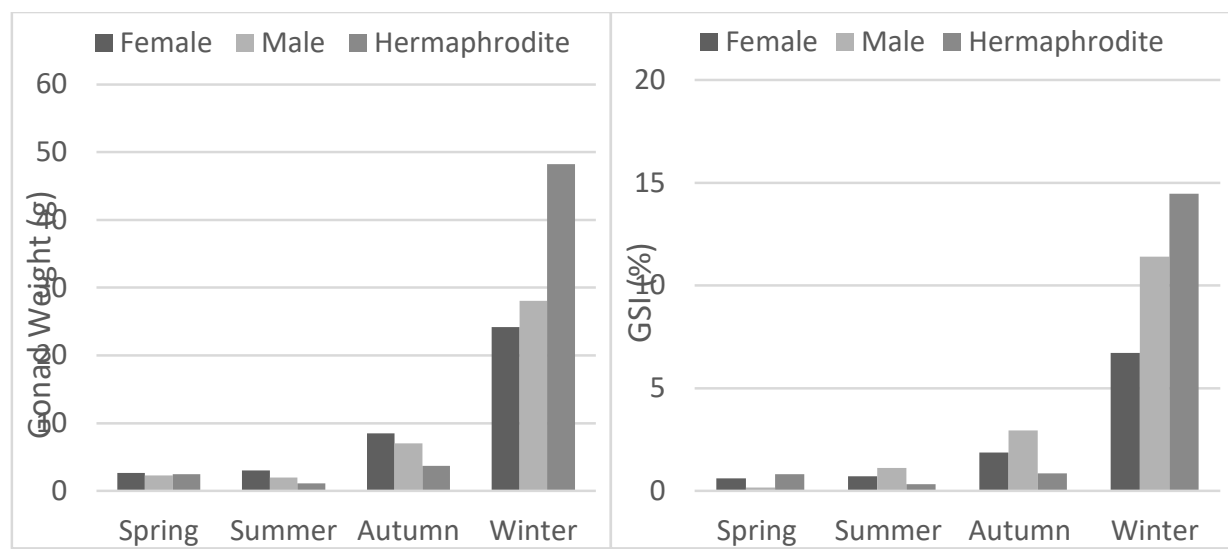

Figure (5): Gonad weight values (g) of different gender of Gilthead sea bream $S$. aurata specimens collected

Figure (6): GSI values (\%) of different gender of Gilthead sea bream $S$. aurata specimens collected in different

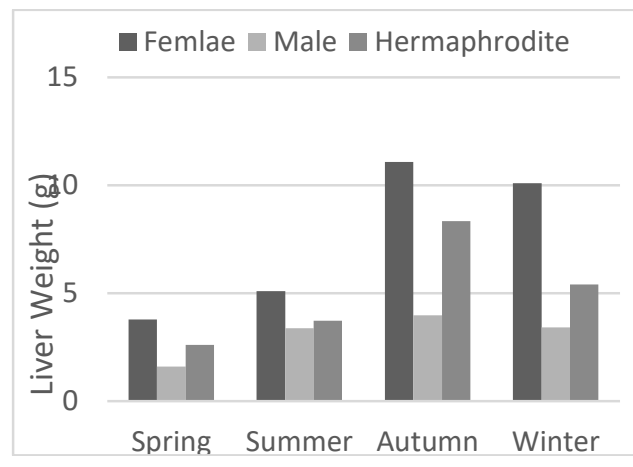

Figure (7): Liver weight values (g) of different gender of Gilthead sea bream $S$. aurata specimens collected in different seasons.

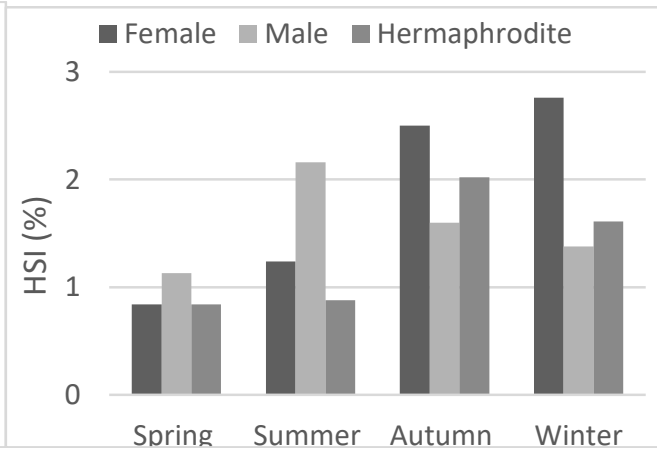

Figure (8): HSI values (\%) of different gender of Gilthead sea bream $S$. aurata specimens collected in different seasons. 


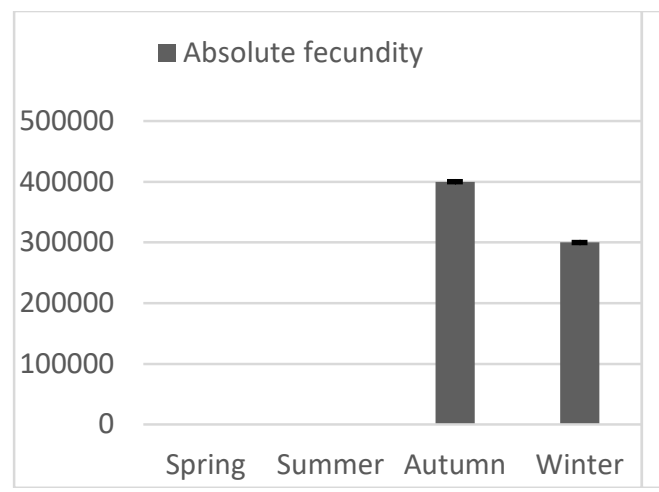

Figure (9): Seasonal variations of absolute fecundity of gilthead seabream $S$. aurata. Data are expressed as mean \pm SE.

\section{Discussion}

In the present study, Broodstock weight and length were recorded different values with different sex, female weight values was higher than male and hermaphrodite. Male recorded the lowest values in weight and length. In autumn females and hermaphrodites were recorded higher weight and length values than others seasons but males recorded their high values in summer.

Condition factor: In the present study, $\mathrm{k}$ factor was peaked in the winter in the different sex female, male and hermaphrodite when spawning season occurred, that related high weight due to the development of gonad that mature in spawning season. Our results was agreed with Chaoui et al. (2006) and Oudjane et al. (2017) who reported that the seasonal evolution of the condition coefficient (K) revealed significant variations in both sexes, indicating that this coefficient is affected by the maturation of genital products. This is n egg diameter (mm)

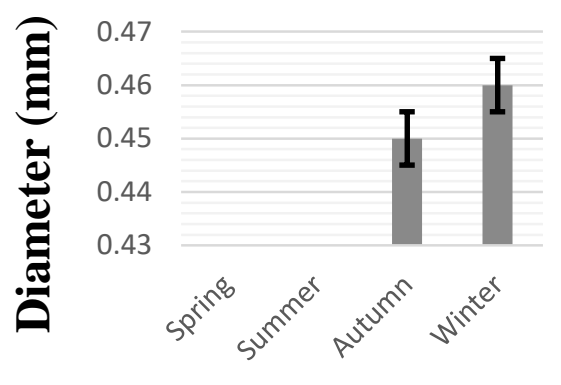

Figure (10): Seasonal variations of egg diameter $(\mathrm{mm})$ of gilthead seabream $S$. aurata. Data are expressed as mean $\pm \mathrm{SE}$.

the case for $S$. aurata of fish in the Mellah lagoon (Northeast, Algeria).

In the case of Puntius puntius (Bhatnagar, 1963) and Micropogonias furnieri (Vazzoler and Braga, 1983), the condition factor decreases at the start of the spawning period due to very high metabolic rates. There is normally a gradual increase in the condition factor during the reproductive period and normalization occurs immediately afterwards.

Gonadosomatic index (GSI): GSI was peaked in the winter (Spawning season) in the three different sex, related to gonad weight that was large in season filled with eggs, sperms and both in hermaaphrodites, that was in agreement with Mehanna (2007) who showed that the monthly variation in GSI values and the distribution of different maturity stages revealed that the spawning activity continued from November to February peaking in December.

Liver weight and hepatosomatic index (HSI): The present study showed 
liver weight peak in the autumn and began decline in the winter and HSI was slightly higher in the winter (spawning season) than in autumn that may be related that the feed intake of broodstock during spawning season was very low, so fish feed before spawning and storage feed and energy in liver for using during spawning which need high demand of energy that was in agreement with Oudjane et al. (2017) who reported that the monthly variations of the HSI in both sexes of the sea bream on the coast of Skikda (in Algeria) indicate that the storage of energy reserves in the liver takes place at the same time as the maturation of the gonads. The end of this last phase of the sexual cycle coincides, in the females, with the exhaustion of their liver reserves

Seasonal fluctuations in the levels of some metabolic enzymes have also been shown along the annual reproductive cycle of fish (Tripathi and Verma, 2004). During maturation, female teleosts require large quantities of nutrients for transfer to the developing oocytes (Sorbera et al., 1998 and Almansa et al., 1999).

The study of gilthead sea bream showed an increase of gonads, liver and muscle lipid content, GSI and HSI between June (post-spawning) and December (pre-spawning) in the four groups and suggests that, independently of the age of the reproductive females, during this period, endogenous nutrients are not applied to ovarian growth. Hence, dietary uptake provides for ovarian growth and the accumulation of lipid reserves in the liver and muscle.
Previous studies of this species have shown that during the ovarian growth phase no specific constituents are preferentially stored or utilized in the body tissues (Harel et al., 1994 and Jerez et al., 2006).

Body size, reproduction, and sex can influence the depletion in lipids experienced by brook trout during winter. For example, we found that larger reproductive individuals lost proportionately more lipids, relative to body size, during winter than smaller reproductive trout, although such an effect of body size was not evident among non-reproductive individuals. This evidence of increased lipid losses with increasing body size might reflect an age-specific increase in reproductive effort (e.g. gonads as a percentage of body size increase with age in some brook trout populations (Hutchings, 1993 and Hutchings et al., 1999).

Absolute fecundity: In teleosts, reproduction and egg and larval quality have been linked to factors such as age, size and broodstock nutrition. In the present study, the absolute fecundity higher in autumn than in winter could be linked to fish size due to the weight and length values obtained in autumn were higher than the values of winter. In general, absolute fecundity increases with age or size or both factors of females (Hattori, 1995 and Adámek et al., 2004).

Egg diameter: According to Morretti (1999), average oocyte size of gilthead seabream was $500 \mu \mathrm{m}(0.5 \mathrm{~mm})$. In this study, the egg diameter is slightly higher in winter than autumn that may be related to female age that recorded high 
value in the winter, this was in agreement with Jerez et al. (2012) who reported that egg diameter and larval length were affected by female age. The difference of egg diameter may be also related to spawning season. Egg diameter, larval length and yolk sac volume have been associated to female age and size for some species ( Kennedy et al., 2007 and Quintero et al., 2011).

Conclusion: The present work focused on key reproductive activity in the gonad of commercially important Sparidea fish $S$. aurata to simply describe sexual pattern. The sex ratio was shifted towards the dominance of females. Identification of hermaphroditism and sex inversion features can allow improvements in fisheries' conservation management and future broodstock selection for aquaculture intentions. $S$. aurata of the studied area spawns eggs in the winter. Spawning is triggered by lower water temperatures.

\section{References}

Adámek, Z., Andreji, J., Henshaw, A. (2004): Stripping fecundity of common bream (Abramis brama L.) from the rivers Trent and Sow (Nottinghamshire, UK). Aquaculture International 12, 133137.

Albertine-Berhaut, J. (1973): Biologie des stades juveniles de téleostéens Mugilidae Mugil auratus Risso 1810, Mugil capito Cuvier 1829 et Mugil saliens Risso 1810: I. Régime alimentaire. Aquaculture 2, 251-266.

Almansa, E., Pérez, M.J., Cejas, J.R., Badía, P., Villamandos, J.E.,
Lorenzo, A. (1999): Influence of broodstock gilthead seabream (Sparus aurata L.) dietary fatty acids on egg quality and egg fatty acid composition throughout the spawning season. Aquaculture 170, 323-336.

Amein, A. (1996): A study of the biology and population dynamics of Litherinus bungus (Forsskal, 1775) in the Gulf of Suez, Egypt, M. Sc. Thesis, Marine Science Department, Faculty of Science, Suez Canal university, Egypt.

Anderson, R., Gutreuter, S., Nielsen, L., Johnson, D. (1983): Fisheries techniques. American Fisheries Society, Bethesda Maryland. Brown, EE and Gratzek, JB (1980). In Fish Farmin, Handbook, 237-337.

Angelescu, V., Gneri, F.S., Nani, A. (1958): La merluza del mar argentino (biología y taxonomía).

Bal, D., Rao, K. (1984):: Marine fisheries,(Ed.) Tata McGraw Hill Publishing Company Ltd. New Delhi 455.

Bhatnagar, G. (1963): On some aspects of the biology of Puntius kolus (Sykes) of the Tungabhadra Reservoir. Indian J. Fish 10, 500-520.

Chaoui, L., Kara, M.H., Faure, E., Quignard, J.P. (2006): Growth and reproduction of the gilthead seabream Sparus aurata in Mellah lagoon (northeastern Algeria). Scientia Marina 70, 545-552.

Duncan, D.B. (1955): Multiple range and multiple F test. Biometrics 11, 344358.

Dytham, C. (1999): Choosing and using statistics: a biologist's guide. Wiely- Blackwell Science. New York. P 320 
Harel, M., Tandler, A., Kissil, G.W., Applebaum, S.W. (1994): The kinetics of nutrient incorporation into body tissues of gilthead seabream (Sparus aurata) females and the subsequent effects on egg composition and egg quality. British Journal of Nutrition 72, 45-58.

Hastings, W., Dickie, L. (1972): Feed formulation and evaluation. Fish nutrition, 327-374.

Hattori, T. (1995): Fecundity of spawning pacific cod (Gadus macrocephalus) in Mutsu Bay, Japan. Bull. Tohoku Natl. Fish. Res. Inst. 57, 1-5.

Hunter, J.R. (1992): Fecundity, spawning, and maturity of female Dover sole Microstomus pacificus, with an evaluation of assumptions and precision. Fish. Bull.(Wash. DC) 90, 101-128.

Hutchings, J.A. (1993): Adaptive life histories effected by age-specific survival and growth rate. Ecology 74, 673-684.

Hutchings, J.A., Pickle, A., McGregor-Shaw, C., Poirier, L. (1999): Influence of sex, body size, and reproduction on overwinter lipid depletion in brook trout. Journal of fish biology 55, 1020-1028.

Jerez, S., Rodriguez, C., Cejas, J., Bolanos, A., Lorenzo, A. (2006): Lipid dynamics and plasma level changes of $17 \beta$-estradiol and testosterone during the spawning season of gilthead seabream (Sparus aurata) females of different ages. Comparative Biochemistry and Physiology Part B: Biochemistry and Molecular Biology 143, 180-189.
Jerez, S., Rodríguez, C., Cejas, J., Martín, M., Bolaños, A., Lorenzo, A. (2012): Influence of age of female gilthead seabream (Sparus aurata L.) broodstock on spawning quality throughout the reproductive season. Aquaculture 350, 54-62.

Kennedy, J., Geffen, A., Nash, R. (2007): Maternal influences on egg and larval characteristics of plaice (Pleuronectes platessa L.). Journal of Sea Research 58, 65-77.

Lloris, D. (2005): A world overview of species of interest to fisheries. Chapter: Sparus aurata. FIGIS Species Fact Sheets. Species Identification and Data Programme-SIDP, FAO-FIGIS. Retrieved on 8 July 2005, 2384. 2383p. Mehanna, S.F. (2007): A preliminary assessment and management of gilthead bream Sparus aurata in the Port Said fishery, the Southeastern Mediterranean, Egypt. Turkish Journal of Fisheries and Aquatic Sciences 7.

Morretti, A. (1999): Manual on hatchery production of seabass and gilthead seabream. Food \& Agriculture Org.

Mylonas, C., Cardinaletti, G., Sigelaki, I., Polzonetti-Magni, A. (2005): Comparative efficacy of clove oil and 2-phenoxyethanol as anesthetics in the aquaculture of European sea bass (Dicentrarchus labrax) and gilthead sea bream ( Sparus aurata) at different temperatures.

Oudjane, F., Bourenane, N., Wafa, T. (2017): Feeding habits and condition of the seabream Sparus aurata Linnaeus, 1758 (Perciformes Sparidae) in the gulfs of Skikda and Annaba (Northeast of Algeria). Mollusca 61, 28.13-51.436. 
Quintero, H., Durland, E., Allen Davis, D., Dunham, R. (2011): Effect of lipid supplementation on reproductive performance of female channel catfish, Ictalurus punctatus, induced and strip-spawned for hybridization. Aquaculture Nutrition 17, 117-129.

Sola, L., Moretti, A., Crosetti, D., Karaiskou, N., Magoulas, A., Rossi, A., Rye, M., Triantafyllidis, A., Tsigenopoulos, C. (2006): Gilthead seabream-Sparus aurata, Proceedings of the WP1 workshop on Genetics of domestication, breeding and enhancement of performance of fish and shellfish, Viterbo, Italy, pp. 12-17.

Sorbera, L.A., Zanuy, S., Carrillo, M. (1998): A Role for Polyunsaturated Fatty Acids and Prostaglandins in Oocyte Maturation in the Sea Bass (Dicentrarchus labrax) a. Annals of the
New York Academy of Sciences 839, 535-537.

Tripathi, G., Verma, P. (2004): Sexspecific metabolic changes in the annual reproductive cycle of a freshwater catfish. Comparative Biochemistry and Physiology Part B: Biochemistry and Molecular Biology 137, 101-106.

Vazzoler, A.E.A.d.M., Braga, F.M.d.S. (1983): Contribuição para o conhecimento da biologia de Cynoscion jamaicensis (Vaillant \& Bocourt, 1883), na área entre Cabo de São Tomé $\left(22^{\circ} 04^{\prime} \mathrm{s}\right)$ e Torres $\left(29^{\circ} 21^{\prime} \mathrm{S}\right)$, Brasil. Boletim do Instituto Oceanográfico, 125-136.

Zohar, Y. (1989): Endocrinology and fish farming: aspects in reproduction, growth, and smoltification. Fish Physiology and Biochemistry 7, 395405.

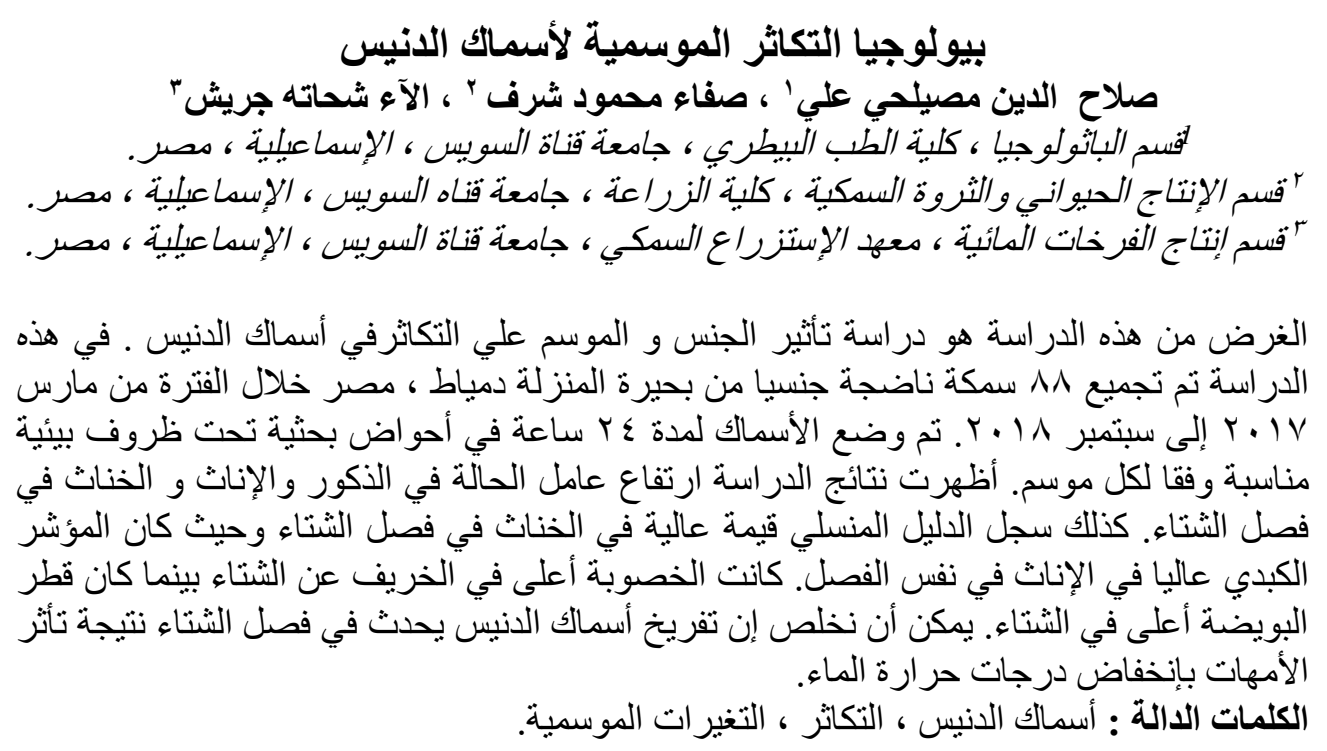

